\title{
2 The MAGOH paralogs - MAGOH, MAGOHB and their multiple isoforms
}

3 Ayushi Rehman ${ }^{1}$, Pratap Chandra ${ }^{1}$ and Kusum Kumari Singh* ${ }^{1}$

$4{ }^{1}$ Department of Biosciences and Bioengineering, Indian Institute of Technology Guwahati,

5 Guwahati-781039, Assam, India; ayushirehman@iitg.ac.in (A.R.); singhpc90@iitg.ac.in (P.C.)

6 kusumsingh@iitg.ac.in (K.K.S.)

7 * Correspondence: kusumsingh@iitg.ac.in; Tel.: +91-(0)-361-2583206; Fax: +91-(0)-361-2582249

8

9

10

11

12

13

14

15

16

17

18

19

20

21 


\section{ABSTRACT}

25 A central processing event in eukaryotic gene expression is splicing. Concurrent with splicing, the 26 core-EJC proteins, eIF4A3 and RBM8A-MAGOH heterodimer are deposited 24 bases upstream of 27 newly formed exon-exon junctions. One of the core-EJC proteins, MAGOH contains a paralog 28 MAGOHB, and this paralog pair is conserved across vertebrates. Upon analysis of the splice variants 29 of MAGOH-paralogs, we have found the presence of alternate protein isoforms which are also 30 evolutionarily conserved. Further, comparison of the amino acid sequence of the principal and 31 alternate protein isoforms has revealed absence of key amino acid residues in the alternate isoforms.

32 The conservation of principal and alternate isoforms correlates to the importance of MAGOH and 33 MAGOHB across vertebrates.

34 Keywords: MAGOH, MAGOHB, EJC, isoforms

35 Abbreviations: EJC - Exon Junction Complex, MAGOH-mago nashi homolog, eIF4A3 - eukaryotic 36 initiation factor 4 A3, RBM8A- RNA binding motif 8A (also known as Y-14) 


\section{INTRODUCTION}

54 The primary step in eukaryotic gene expression involves transcription of DNA into precursor-mRNAs 55 (pre-mRNAs). The pre-mRNAs undergo various post-transcriptional processing events before 56 generating functional protein products. A notable processing event is splicing, where the spliceosome

57 removes introns and ligates exons together. Concurrent with splicing, mature mRNAs are marked 58 with the exon junction complex (EJC) at 24 nucleotides upstream of an exon-exon junction ${ }^{1}$. The EJC 59 forms a gene regulatory nexus composed of many proteins that are grouped under stable core- and 60 transient peripheral-protein complexes. The core-EJC consists of three proteins, eIF4A3 and RBM8A61 MAGOH heterodimer; whereas the peripheral-EJC includes ALYREF, ASAP complex or PSAP 62 complex, and Upf proteins ${ }^{2-6}$. Additional to mRNA processing, the core-EJC proteins have essential 63 functions in brain development and embryonic neurogenesis ${ }^{7}$. In this communication, we will mainly 64 focus on one of the core-EJC proteins, MAGOH.

65 MAGOH (mago nashi homolog) was originally identified in Drosophila melanogaster, where 66 embryos lacking functional mago protein produced sterile progeny. Thus, this protein was named 67 "mago nashi" meaning "without grandchildren" in the Japanese language ${ }^{8}$. MAGOH is well 68 conserved among all vertebrates. It functions to maintain integrity of mRNAs as a part of the EJC as 69 well as the nonsense-mediated mRNA decay (NMD) pathway ${ }^{9}$. The importance of MAGOH in NMD 70 has recently also been characterised in zebrafish ${ }^{10}$. Interestingly, vertebrates contain a paralog of 71 MAGOH, MAGOHB which is also associated with mRNAs via EJC and NMD ${ }^{11}$. In addition to their 72 roles in mRNA processing, the MAGOH paralogs (MAGOH and MAGOHB) have been found to be 73 associated with cancer progression. In cancers with a hemizygous deletion of MAGOH, MAGOHB 74 was suggested as the highest dependent gene. The dependency of MAGOHB in such MAGOH 75 deficient cancers have the potential for cancer treatment ${ }^{12}$. MAGOH paralogs have also been found to 76 be involved in gastric cancers. Importantly, the simultaneous knockdown of MAGOH-MAGOHB in 77 gastric cancer cells exhibited anti-tumor effects via the bRAF/MEK/ERK signalling pathway ${ }^{13}$. Thus, 78 the MAGOH paralogs are essential for proper functioning of cells, yet sufficient information on the 79 architecture and evolutionary conservation of these genes is lacking. Concordant with most 
eukaryotic genes, both the MAGOH-paralogs undergo alternative splicing and produce multiple splice variants, which have not yet been characterised. In this communication, we will discuss the features of the alternate protein isoforms of MAGOH-paralogs in humans and mice. We will also look at structural features of the alternate isoforms compared to the principal MAGOH protein isoform.

\section{RESULTS and DISCUSSION}

\subsection{MAGOH paralogs have multiple protein isoforms in humans}

MAGOH-paralogs belong to the MAGO NASHI protein family, Ensembl ID-PTHR12638. In humans, $M A G O H$ also known as MAGOH1 or MAGOHA is located on the reverse strand of chromosome 1 at 1p32.3 (chr1:53,226,900-53,238,518, GRCh38/hg38). Alternative splicing of $M A G O H$ pre-mRNA generates four transcripts, MAGOH-201, MAGOH-202, MAGOH-203, and MAGOH-204 (Table-1). MAGOH-202 is the primary transcript made of five exons and encodes the principal protein isoform of 146 amino acids (aa). $M A G O H-201$ constitutes four exons and codes for an alternate protein isoform of 109 aa. Comparison of $M A G O H-201$ with $M A G O H-202$ reveals skipping of exon 3 (111 nucleotides) in MAGOH-201, generating the alternate isoform (Figure-1a). The other transcripts, $M A G O H-203$ and $M A G O H-204$ comprise three exons and do not translate into proteins due to the absence of open reading frames (ORF). Hence, $M A G O H$ is transcribed to generate four splice variants, of which two are protein-coding and two are non-coding. The finding of an alternate isoform (109 aa) is interesting as MAGOH is primarily mentioned as a 146 aa protein, with a molecular weight of $17 \mathrm{kDa}^{14,15}$. Subsequent to the finding of an alternate transcript in $M A G O H$, we were interested to find out if its paralog, $M A G O H B$ also produces an alternate transcript.

The $M A G O H B$ gene in humans is located on the reverse strand of chromosome 12 at $12 \mathrm{p} 13.2$ (chr12:10,604,193-10,613,609, GRCh38/hg38). As per the Ensembl genome browser, MAGOHB premRNA generates eleven alternately spliced transcripts (Table-1). Of these eleven transcripts, three have coding potential. Thus, similar to $M A G O H, M A G O H B$ also produces multiple protein coding transcripts. Two of the protein-coding transcripts, MAGOHB-201 and MAGOHB-204, contain five exons. MAGOHB-201 is the primary transcript and codes for the 148 aa primary protein isoform, while the alternate transcript, $M A G O H B-204$ codes for the alternate 102 aa protein isoform. The two 
107 transcripts differ due to the presence of an alternative 5' splice site in the first exon of MAGOHB-204 108 (Figure-1a). The third protein-coding transcript, MAGOHB-211 consists of 2 exons which code for an 10981 aa protein. In the transcript, $M A G O H B-211$, its first exon is similar to the principal isoform, MAGOHB-201, whereas its second exon differs completely due to the presence of an alternate 3 , splice site. $M A G O H B$ thus produces three different protein isoforms. It will be fascinating to analyse whether the alternate protein isoforms are also generated in other species. Apart from these three protein coding transcripts, five other transcripts $(M A G O H B-205,-206,-208,-209,-210)$ are also generated. Out of these five, three transcripts MAGOHB-208, MAGOHB-209 and MAGOHB-205 are made of six exons whereas MAGOHB-206 and MAGOHB-210 are composed of five exons. All the five transcripts are degraded via the NMD pathway due to the presence of premature termination codons (PTCs), which is one of the prerequisites of NMD. Lastly, the remaining three transcripts of MAGOHB, MAGOHB-202, -203, -207 have intron retention (IR), and do not code for any protein. Here, MAGOHB-203 and MAGOHB-207 comprise of three exons whereas MAGOHB-202 is made of two exons. In this article, we will focus only on the protein coding transcripts of both the MAGOHparalogs.

In line with the Ensembl annotation, we will be referring to the protein isoforms according to their transcript IDs. We observed that the two MAGOH protein isoforms, principal isoform-146 aa and alternate isoform-109 aa differ in 37 residues, i.e., amino acids 50-86 of the principal isoform. In case of MAGOHB, three protein isoforms are generated. Coding region of the transcript MAGOHB-204 starts from the second exon, and translates into an alternate protein isoform that varies from the principal protein isoform, MAGOHB-201 in the N-terminus (devoid of residues 1-46). The third protein isoform, MAGOHB-211 differs from the principal isoform in amino acids 38-81 since its second exon is formed by an alternate 3' splice site. The presence of two functionally redundant MAGOH paralogs is in itself fascinating. From this characterisation we also know that both the MAGOH paralogs generate multiple protein isoforms in humans. In the following sections we have 
133 which might hint on an evolutionarily conserved function of the alternate protein isoforms generated 134 by the MAGOH paralogs.

\section{2 $M A G O H B$ codes for multiple protein isoforms in mice}

The MAGOH paralogs are conserved across vertebrates and MAGOH has been widely studied in mice. The presence of multiple protein isoforms of the MAGOH paralogs in humans raised the next question - are such alternate protein isoforms also present in mice? Hence, we analysed the mouse genome on Ensembl for multiple isoforms of MAGOH paralogs (Table-2). Here, we have referred to the mouse orthologs of human MAGOH paralogs as Magoh and Magohb. In mice, Magoh is located on chromosome $4(\mathrm{chr} 4: 107,879,755-107,887,424, \mathrm{GRCm} 38)$, and is transcribed into two transcripts, Magoh-201 and Magoh-202. Magoh-201 is translated into a 146 aa protein, whereas Magoh-202 does not code for any protein because of the absence of an ORF. Therefore, unlike humans, mice do not produce any alternate protein isoform of Magoh. The paralog of Magoh, Magohb is located on the reverse strand of chromosome 6 (chr 6:131,284,388-131,293,244, GRCm38). A total of seven Magohb transcripts are generated in mice, where two transcripts (Magohb-201 and Magohb-205) are protein-coding. Magohb-201 translates into the 148 aa principal protein isoform, whereas Magohb205 codes for the alternate protein isoform of 102 aa. Thus, in humans and mice two protein isoforms of MAGOHB are generated, which are of the same length. Similar to the alternate human MAGOHB transcript, MAGOHB-204, the first exon of Magohb-205 constitutes most of the 5'UTR region and ligates exon 2 via an alternate 5' splice site (Figure-1b). The start codon for Magohb-205 is present in the second exon, thus the protein it encodes is devoid of residues $1-46$ compared to the principal isoform. Curiously, splicing patterns of the two Magohb protein isoforms in mice are very similar to human MAGOHB protein isoforms. Besides the protein-coding transcripts, three transcripts, Magohb202, $-203,-204$, are subjected to degradation via NMD. The remaining two transcripts (Magohb-206 and Magohb-207) retain intronic regions and do not code for any protein. Thus, similar to its human ortholog, Magohb in mice also generates multiple protein-coding and non-coding splice variants.

Altogether, we find $M A G O H$ transcript variants in humans and mice belong to two biotypes- protein coding transcripts and transcripts without an ORF; while $M A G O H B$ transcript variants belong to three 
160 biotypes - protein-coding, NMD-sensitive, and IR. In both the species, $M A G O H$ and MAGOHB

161 generate multiple splice variants. The pattern of splicing for MAGOH-paralogs is similar, as both the 162 species produce protein-coding as well as non-coding transcripts. In general, multiple splice variants 163 tend to increase the proteome diversity of the genome. Among various alternative splicing (AS) 164 events, IR, and AS-NMD are important for post-transcriptional gene regulation ${ }^{16,17}$. It is also likely 165 that transcripts with similar exon-intron structure, referred to as iso-orthologs, have similar biological 166 function ${ }^{18}$. The similarity in splicing pattern as well as length of the alternate protein-coding 167 transcripts prompted us to shift our focus to the sequence conservation of the alternate protein 168 isoforms, discussed in the next section. The reason behind generation of multiple protein-coding and non-coding splice variants of MAGOH-paralogs is not yet known. They may contribute either towards regulation of MAGOH-paralogs or may perform some unexplored function.

\subsection{Alternate isoforms of MAGOH paralogs are conserved across different species}

We have described that MAGOH-paralogs produce more than one protein isoform (Figure-1). In this section, we depict the conserved nature of the alternate protein isoforms. To gain further insight into the conservation of the alternate proteins of MAGOH paralogs, we performed pairwise alignments of the protein sequences in humans and mice. We first compared the principal isoforms of MAGOHparalogs, MAGOH-202 with Magoh-201 and MAGOHB-201 with Magohb-201, followed by comparison of the alternate isoforms of MAGOHB, MAGOHB-204 with Magohb-205.

The principal isoforms of MAGOH in humans and mice are $100 \%$ identical (Figure-2a), whereas in the case of MAGOHB the identity is $98 \%$, owing to three different residues, i.e., amino acids $2-4$ (Figure-2b). Conservation of the primary isoforms is evident due to their suggested roles in EJC and NMD ${ }^{11,19}$. Proceeding to the alternate protein isoforms, as discussed above, the alternate protein of MAGOH (MAGOH-201, 109 aa) does not have any ortholog in mice, meaning this isoform is either not important or might be specifically generated in higher vertebrates including humans. Interestingly, the 102 aa MAGOHB proteins in humans and mice are 100\% identical to each other (Figure-2c). The striking identity prompted us to analyze other species for the presence of alternate isoforms of 
187 multiple sequence alignment of the protein sequence. Quite interestingly, the alternate isoforms of the 188 MAGOH-paralogs are conserved across vertebrates (Table 3). Though the alternate isoform of 189 MAGOH, 109 aa is not present in mice, it is present in 52 other species, where the protein sequence 190 differs only at position 2 (Supplementary Figure-1 and 2). The alternate isoform of MAGOHB ,102 aa, is present in 11 different species and is $100 \%$ identical in 10 species, but differs in the alternate isoform of kangaroo rat- Dipodomys ordii at position 25 and 35 . We have also validated the expression of the conserved alternate protein-coding transcripts, $M A G O H-201$ and MAGOHB-204 in HEK-293 cells via RT-PCR (Figure-3a). We further performed a phylogenetic analysis of cDNA sequence from four species having alternate isoforms for both MAGOH and MAGOHB (highlighted in Table 3). The tree estimated via maximum likelihood shows the isoforms clustered into two groups, specific for MAGOH and MAGOHB. This indicates that similar to the principal isoforms, the alternate isoforms are also evolutionarily conserved orthologs (Figure-3b). The conservation of the alternate protein isoforms of MAGOH paralogs across species is quite riveting. Consequently, an evolutionary pressure must have resulted in conservation of the alternate protein isoforms of both the MAGOH-paralogs. It has been previously pointed that an identity in the range of $50 \%-70 \%$ is the defining boundary of protein conservation, and function of conserved proteins is generally expected to be preserved above $70 \%$ identity ${ }^{20}$. Thus, the presence of a conserved alternate isoform of MAGOH and MAGOHB does not seem to be a mere coincidence and might involve a functional role, yet unexplored. Due to the difference in the residues of the principal and alternate isoforms of MAGOH paralogs, there might exist structural and functional differences between them which we have elaborated below.

The structure of MAGOH is composed of three $\alpha$ helices and six $\beta$ strands that form an extended sheet ${ }^{15}$. The helices form a hydrophobic core to interact with the RNA-binding domain of Y-14, which is primarily involved in protein-protein interactions. The extended $\beta$ sheet contains conserved residues, forming the binding platform for EJC factors or other associated proteins ${ }^{15,19}$. On aligning the principal and alternate protein isoforms in humans, we found the alternate isoform of MAGOH to 
214 isoform has $68.9 \%$ sequence identity to the principal MAGOHB isoform (Figure-2d, 2e). Comparison 215 of structural features is shown in Figure-4. As shown, the alternate isoform of MAGOH lacks residues 216 50-86 corresponding to the principal MAGOH isoform, MAGOH-202. These residues constitute a 217 portion of the $\alpha_{1}$ helix of MAGOH. Helix $\alpha_{1}$ with helix $\alpha_{3}$ form a part of the hydrophobic core which binds the RNA-binding domain (RBD) of Y-14. Consequently, the alternate isoform, MAGOH-201, might lack the ability to bind Y-14 or may bind to it without masking Y-14's RBD. If the alternate isoform of MAGOH binds Y-14 it will be interesting to find out the stability and possible function of this alternate heterodimer complex.

The N-terminus of the principal MAGOH isoform contains conserved residues, Tyr6, Tyr10, and Phe21 of the $\beta$-sheet ${ }^{15}$. Since the alternate isoform of MAGOHB, MAGOHB-204, lacks residues 146, it also lacks these conserved residues present in the $\beta$ sheet. Consequently, mutations in residues $16 / 17,20,39 / 40,41 / 42$ of the principal MAGOH protein result in loss of interaction with pre-mRNA, spliced mRNA as well as EJC components, BTZ, UPF3b and eIF4A3, whereas interaction with Y-14 and PYM remains intact ${ }^{21}$. Thus, MAGOHB-204 might have functional Y-14 binding but may lack binding with other EJC factors.

To summarize, we find that the generation of alternate protein isoforms by MAGOH-paralogs is not only limited to humans, but also extends to other species. The high degree of conservation of the alternate protein isoforms, MAGOH-201 (109 aa) and MAGOHB-204 (102 aa), may point out to the presence of an evolutionary pressure maintaining multiple isoforms of MAGOH and MAGOHB. These alternate protein isoforms might be involved in regulating the levels of principal MAGOH proteins or may have functions entirely different from the principal isoforms. the primary and alternate protein isoforms. Hence, the function of the alternate isoforms might need to

237 be analysed in conditions where the principal isoform is absent, and is the subject of further experimentations.

\section{MATERIALS AND METHODS}




\subsection{Sequence information for isoforms}

241 All the sequence information for Homo sapiens and Mus musculus were taken from Ensembl (Release

242 101) (https://asia.ensembl.org/index.html) ${ }^{22}$. The Ensembl IDs are - ENSG00000162385(MAGOH),

243 ENSG00000111196(MAGOHB) for human MAGOH paralogs, and

244 ENSMUSG00000028609(Magoh), ENSMUSG00000030188(Magohb) for Magoh paralogs in mice.

245 Genome assembly versions referred were Human-GRCh38.p13 and Mouse-GRCm38.p6.

$246 \quad 3.2$ Sequence alignment

247 Alignments were generated using the CLC Main Workbench's alignment tool and the identity among 248 aligned proteins was analysed using the EMBOSS Needle pairwise alignment tool ${ }^{23}$. The proteins 249 were aligned with the BLOSUM62 matrix. Gap opening penalty was kept at 10 and gap extension 250 penalty at 0.5 . Multiple sequence alignments of the alternate isoforms (109 aa and 102 aa) were 251 performed using ClustalW in the MEGA-X ${ }^{24}$ tool with the following parameters- gap opening penalty 252 10.00, gap extension penalty 0.20. Jalview was used for visualisation of the multiple sequence 253 alignments ${ }^{25}$. Phylogenetic trees were generated using MEGA-X as previously described ${ }^{26}$, briefly the 254 cDNA sequence was downloaded from Ensembl, codons aligned using MUSCLE followed by model 255 generation and using the highest model to estimate the phylogenetic tree via maximum likelihood.

$256 \quad 3.3$ Isoform expression analysis

257 RNA for isoform analysis was extracted from HEK-293 cells, cultured in DMEM at $37^{\circ} \mathrm{C}$ in a 258 humidified $\mathrm{CO}_{2}$ incubator. The RNA was converted into cDNA using the Super Reverse Transcriptase 259 MuLV cDNA kit (Biobharati). The primers sequence for the principal isoform were used as described 260 previously $^{11}$. Primer sequences for the alternate isoforms are mentioned in the supplementary file.

\section{ACKNOWLEDGEMENT}

262 We would like to thank all the members of the KKS lab for their helpful suggestions, especially 263 Bhagyashree Deka for her insightful comments on the manuscript. A.R. and P.C. are funded under 264 the scholarships provided by Ministry of Human Resource Development (MHRD), Govt. of India. 265 K.K.S. acknowledges funding from the Science \& Engineering Research Board (SERB), Government 
266 of India [Grant No. CRG/2019/001352]. We would also like to thank the Indian Institute of

267 Technology, Guwahati for providing required resources.

268 CONFLICTS OF INTEREST

269 The authors declare no competing conflicts.

\section{REFERENCES}

1. Singh G, Kucukural A, Cenik C, Leszyk JD, Shaffer SA, Weng Z, Moore MJ. The cellular EJC interactome reveals higher-order mRNP structure and an EJC-SR protein nexus. Cell 151, 750764 (2012). doi: 10.1016/j.cell.2012.10.007

2. Tange TØ, Shibuya T, Jurica MS, Moore MJ. Biochemical analysis of the EJC reveals two new factors and a stable tetrameric protein core. RNA 11, 1869-1883 (2005). doi: 10.1261/rna.2155905.

3. Kataoka N, Diem MD, Kim VN, Yong J, Dreyfuss G. Magoh, a human homolog of Drosophila mago nashi protein, is a component of the splicing-dependent exon-exon junction complex. EMBO J. 20, 6424-33 (2001). doi: 10.1093/emboj/20.22.6424.

4. Wang Z, Ballut L, Barbosa I, Le Hir H. Exon Junction Complexes can have distinct functional flavours to regulate specific splicing events. Sci Rep. 8, 9509 (2018). doi: 10.1038/s41598-01827826-y.

5. Le Hir H, Izaurralde E, Maquat LE, Moore MJ. The spliceosome deposits multiple proteins 20-24 nucleotides upstream of mRNA exon-exon junctions. EMBO J. 19, 6860-9 (2000). doi: 10.1093/emboj/19.24.6860.

6. Le Hir H, Gatfield D, Braun IC, Forler D, Izaurralde E. The protein Mago provides a link between splicing and mRNA localization. EMBO Rep. 2, 1119-24 (2001). doi: 10.1093/emboreports/kve245.

7. McMahon JJ, Miller EE, Silver DL. The exon junction complex in neural development and neurodevelopmental disease. Int $J$ Dev Neurosci. 55, 117-123 (2016). doi: 10.1016/j.ijdevneu.2016.03.006. Epub 2016 Apr 9. PMID: 27071691.

8. Boswell RE, Prout ME, Steichen JC. Mutations in a newly identified Drosophila melanogaster gene, mago nashi, disrupt germ cell formation and result in the formation of mirror-image symmetrical double abdomen embryos. Development. 113, 373-84 (1991). Erratum in: Development 1991 Dec;113(4):precedi. PMID: 1765008.

9. Gehring NH, Kunz JB, Neu-Yilik G, Breit S, Viegas MH, Hentze MW, Kulozik AE. Exonjunction complex components specify distinct routes of nonsense-mediated mRNA decay with 
differential cofactor requirements. Molecular cell. 20, 65-75 (2005). doi: 10.1016/j.molcel.2005.08.012. PMID: 16209946.

10. Gangras P, Gallagher TL, Parthun MA, Yi Z, Patton RD, Tietz KT, Deans NC, Bundschuh R, Amacher SL, Singh G. Zebrafish rbm8a and magoh mutants reveal EJC developmental functions and new 3'UTR intron-containing NMD targets. PLoS genetics. 16, e1008830 (2020). doi: 10.1371/journal.pgen.1008830. PMID: 32502192; PMCID: PMC7310861.

11. Singh KK, Wachsmuth L, Kulozik AE, Gehring NH. Two mammalian MAGOH genes contribute to exon junction complex composition and nonsense-mediated decay. RNA Biology 10, 12911298 (2013).

12. Viswanathan SR, Nogueira MF, Buss CG, Krill-Burger JM, Wawer MJ, Malolepsza E, Berger AC, Choi PS, Shih J, Taylor AM, Tanenbaum B, Pedamallu CS, Cherniack AD, Tamayo P, Strathdee CA, Lage K, Carr SA, Schenone M, Bhatia SN, Vazquez F, Tsherniak A, Hahn WC, Meyerson M. Genome-scale analysis identifies paralog lethality as a vulnerability of chromosome $1 \mathrm{p}$ loss in cancer. Nature Genetics 50, 937-943 (2018). doi: 10.1038/s41588-018-0155-3. PMID: 29955178; PMCID: PMC6143899.

13. Zhou Y, Li Z, Wu X, Tou L, Zheng J, Zhou D. MAGOH/MAGOHB Inhibits the Tumorigenesis of Gastric Cancer via Inactivation of b-RAF/MEK/ERK Signaling. OncoTargets and therapy 13, 12723-12735 (2020). doi: 10.2147/OTT.S263913. PMID: 33328743; PMCID: PMC7735944.

14. Zhao XF, Colaizzo-Anas T, Nowak NJ, Shows TB, Elliott RW, Aplan PD. The mammalian homologue of mago nashi encodes a serum-inducible protein. Genomics. 47, 319-22 (1998). doi: 10.1006/geno.1997.5126.

15. Lau CK, Diem MD, Dreyfuss G, Van Duyne GD. Structure of the Y14-Magoh core of the exon junction complex. Curr Biol. 13, 933-41 (2003). doi: 10.1016/s0960-9822(03)00328-2.

16. McGlincy NJ, Smith CW. Alternative splicing resulting in nonsense-mediated mRNA decay: what is the meaning of nonsense? Trends Biochem Sci.33, 385-93 (2008). doi: 10.1016/j.tibs.2008.06.001.

17. Jacob AG, Smith CWJ. Intron retention as a component of regulated gene expression programs. Hum Genet. 136, 1043-1057 (2017). doi: 10.1007/s00439-017-1791-x.

18. Zambelli F, Pavesi G, Gissi C, Horner DS, Pesole G. Assessment of orthologous splicing isoforms in human and mouse orthologous genes. BMC Genomics. 11, 534 (2010). doi: 10.1186/1471-2164-11-534.

19. Fribourg S, Gatfield D, Izaurralde E, Conti E. A novel mode of RBD-protein recognition in the Y14-Mago complex. Nat Struct Biol. 10, 433-9 (2003). doi: 10.1038/nsb926.

20. Morata J, Béjar S, Talavera D, Riera C, Lois S, de Xaxars GM, de la Cruz X. The relationship between gene isoform multiplicity, number of exons and protein divergence. PLoS One. 8, e72742 (2013). doi: 10.1371/journal.pone.0072742. 
21. Gehring NH, Lamprinaki S, Hentze MW, Kulozik AE. The hierarchy of exon-junction complex assembly by the spliceosome explains key features of mammalian nonsense-mediated mRNA decay. PLoS Biol. 7 e1000120 (2009). doi: 10.1371/journal.pbio.1000120.

22. Yates AD, Achuthan P, Akanni W, Allen J, Allen J, Alvarez-Jarreta J, Amode MR, Armean IM, Azov AG, Bennett R, Bhai J, Billis K, Boddu S, Marugán JC, Cummins C, Davidson C, Dodiya K, Fatima R, Gall A, Giron CG, Gil L, Grego T, Haggerty L, Haskell E, Hourlier T, Izuogu OG, Janacek SH, Juettemann T, Kay M, Lavidas I, Le T, Lemos D, Martinez JG, Maurel T, McDowall M, McMahon A, Mohanan S, Moore B, Nuhn M, Oheh DN, Parker A, Parton A, Patricio M, Sakthivel MP, Abdul Salam AI, Schmitt BM, Schuilenburg H, Sheppard D, Sycheva M, Szuba M, Taylor K, Thormann A, Threadgold G, Vullo A, Walts B, Winterbottom A, Zadissa A, Chakiachvili M, Flint B, Frankish A, Hunt SE, IIsley G, Kostadima M, Langridge N, Loveland JE, Martin FJ, Morales J, Mudge JM, Muffato M, Perry E, Ruffier M, Trevanion SJ, Cunningham F, Howe KL, Zerbino DR, Flicek P. Ensembl 2020. Nucleic Acids Res. 48, D682-D688 (2020). doi: 10.1093/nar/gkz966.

23. Madeira F, Park YM, Lee J, Buso N, Gur T, Madhusoodanan N, Basutkar P, Tivey ARN, Potter SC, Finn RD, Lopez R. The EMBL-EBI search and sequence analysis tools APIs in 2019. Nucleic Acids Res. 47, W636-W641 (2019). doi: 10.1093/nar/gkz268.

24. Kumar S, Stecher G, Li M, Knyaz C, Tamura K. MEGA X: Molecular Evolutionary Genetics Analysis across Computing Platforms. Mol Biol Evol. 35, 1547-1549 (2018). doi: 10.1093/molbev/msy096.

25. Waterhouse AM, Procter JB, Martin DMA, Clamp M, Barton GJ. Jalview Version 2 - a multiple sequence alignment editor and analysis workbench. Bioinformatics 25, 1189-1191(2009).doi: 10.1093/bioinformatics/btp033s

26. Barry G Hall. Building Phylogenetic Trees from Molecular Data with MEGA. Molecular Biology and Evolution 30, 1229-1235 (2013). doi: 10.1093/molbev/mst012. 

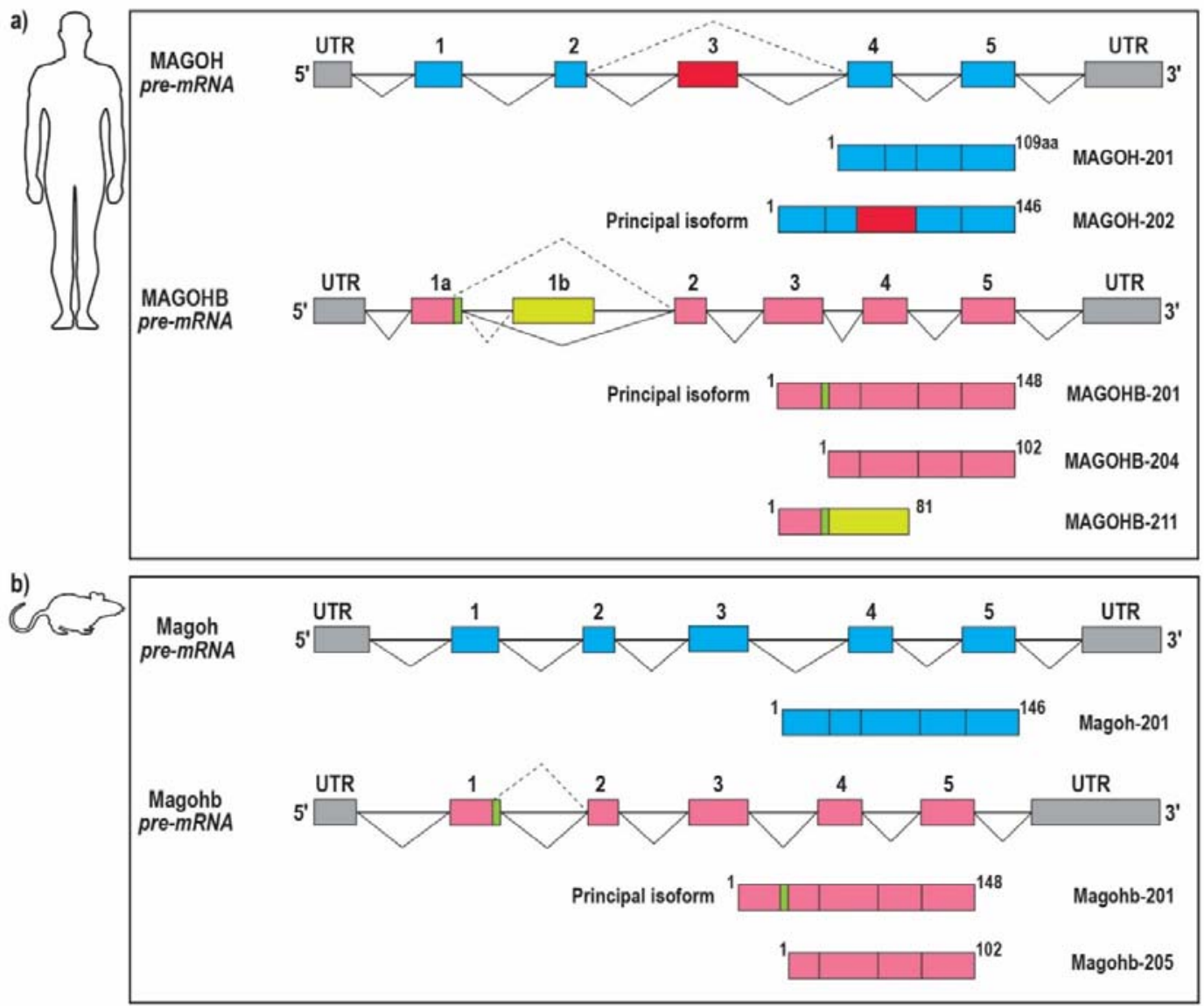

370 Figure 1- Isoforms of MAGOH-paralogs in (a) humans and (b) mice. The pre-mRNA generated 371 from each gene is shown on top, where boxes represent exons, and introns are represented by horizontal lines. Constitutive splicing is denoted with solid lines, while alternative splicing is denoted

373 with dashed lines. MAGOH is represented in blue and MAGOHB is represented in pink. The pre374 mRNA shown here includes exons of the protein-coding transcripts. Principal and alternate protein 375 isoforms are shown below each pre-mRNA, where each box represents coding exons from the premRNA. 


\begin{tabular}{|c|c|}
\hline a) & 40 \\
\hline $\begin{array}{r}\text { MAGOH-202 } \\
\text { Magoh-201 }\end{array}$ & $\begin{array}{l}\text { MESDFYLRYYVGHKGKF GHEFLEFEFRPDGKLRYANNSNYKNDVM IRKEAYVHKSVMEELR I IDDSE IT } \\
\text { MESDFYLRYYVGHKGKFGHEFLEFEFRPDGKLRYANNSNYKNDVMIRKEAYVHKSVMEELKR I DDSE I }\end{array}$ \\
\hline & $\begin{array}{lccc}80 & 100 & 120 & 140 \\
1 & 1 & 140\end{array}$ \\
\hline MAGOH-202 & KEDDALWPPPDRVGRQELE IVIGDEH ISFTTSKI GSLI DVNQSKDPEGLRVFYYLVQDLKCLVFSLIGLH \\
\hline Magoh-201 & KEDDALWPPPDRVGRQELE IVI GDEH ISFTTSK I GSLI DVNQSKDPEGLRVFYYLVQDLKCLVFSLIGLH \\
\hline MAGOH-202 & FKIKPI 146 \\
\hline Magoh-201 & FKIKPI 146 \\
\hline
\end{tabular}

\begin{tabular}{|c|c|}
\hline b) & 40 \\
\hline $\begin{array}{r}\text { MAGOHB-201 } \\
\text { Magohb-201 }\end{array}$ & $\begin{array}{l}\text { MAVASDFYLRYYVGHKGKFGHEFLEFEFRPDGKLRYANNSNYKNDVM I RKEAYVHKSVMEELKR I IDDSE } \\
\text { MSMGSDFYLRYYVGHKGKFGHEFLEFEFRPDGKLRYANNSNYKNDVM I RKEAYVHKSVMEELKR I IDDSE }\end{array}$ \\
\hline & $\begin{array}{llll}80 & 100 & 120 & 140\end{array}$ \\
\hline $\begin{array}{l}\text { MAGOHB-201 } \\
\text { Magohb-201 }\end{array}$ & 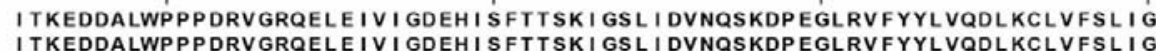 \\
\hline Magohb-201 & I TKEDDALWPPPDRVGRQELEIVI GDEHISFTTSKIGSLI DVNQSKDPEGLRVFYYLVQDLKCLVFSLIG \\
\hline MAGOHB-201 & LHFKIKP I 148 \\
\hline Magohb-201 & LHFKIKP I 148 \\
\hline
\end{tabular}

\begin{tabular}{|c|c|}
\hline c) & 40 \\
\hline $\begin{array}{r}\text { MAGOHB-204 } \\
\text { Magohb-205 }\end{array}$ & 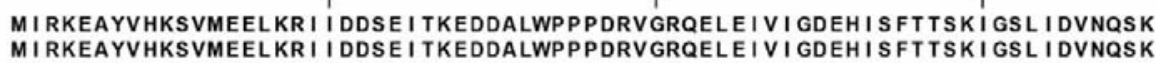 \\
\hline & 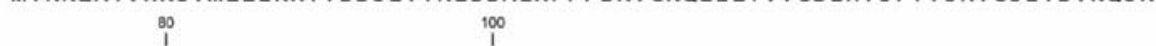 \\
\hline MAGOHB-204 & DPEGLRVFYYLVQDLKCLVFSLIGLHFKIKP I 102 \\
\hline Magohb-205 & DPEGLRVFYYLVQDLKCLVFSLIGLHFKIKP I 102 \\
\hline
\end{tabular}

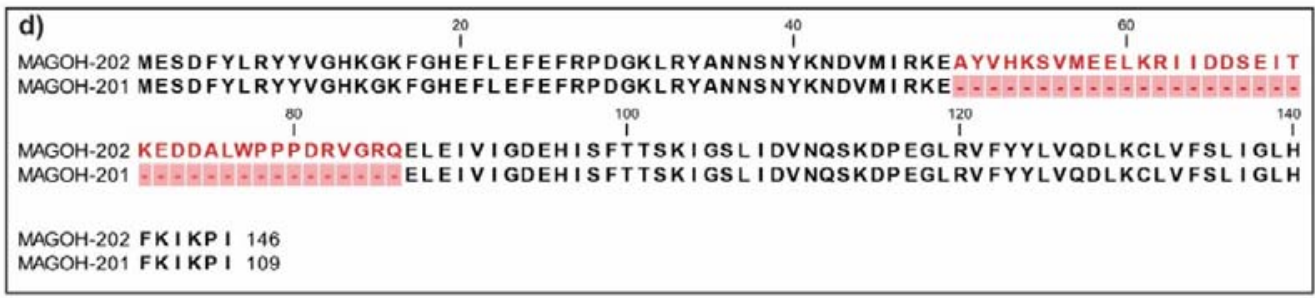

\begin{tabular}{|c|c|}
\hline e) & $\stackrel{20}{11} \quad \frac{40}{1}$ \\
\hline MAGOHB-201 & MAVASDFYLRYYVGHKGKFGHEFLEFEFRPDGKLRYANNSNYKNDVM IRKEAYVHKSVMEELKRIIDDSE \\
\hline MAGOHB-204 & 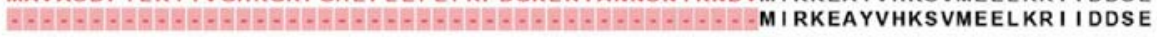 \\
\hline & $\begin{array}{llll}80 & 100 & 120 & 140 \\
1 & 1 & 1\end{array}$ \\
\hline MAGOHB-201 & I TKEDDALWPPPDRVGRQELEIVIGDEHISFTTSKIGSLIDVNQS KDPEGLRVFYYLVQDLKCLVFSLIG \\
\hline MAGOHB-204 & I TKEDDALWPPPDRVGRQELEIVIGDEH ISFTTSKIGSL I DVNQS KDPEGLRVFYYLVQDLKCLVFSLIG \\
\hline MAGOHB-201 & LHFK IKP I 148 \\
\hline MAGOHB-204 & LHFKIKPI 102 \\
\hline
\end{tabular}

385 Figure 2- Pairwise alignment of MAGOH protein isoforms. The protein isoform alignments were 386 generated using the CLC Main Workbench. a) MAGOH principal isoform alignment in humans 387 (MAGOH-202) and mice (Magoh-201) b) MAGOHB principal isoform alignment in humans 388 (MAGOHB-201) and mice (Magohb-201) c) MAGOHB alternate isoform alignment in humans 389 (MAGOHB-204) and mice (Magohb-205). The principal and alternate isoforms of $390 \mathrm{MAGOH} / \mathrm{MAGOHB}$ in humans were also aligned to each other to analyse similarity - d) MAGOH 391 principal isoform (MAGOH-202) aligned with alternate isoform (MAGOH-201) e) MAGOHB principal isoform (MAGOHB-201) aligned with its alternate isoform (MAGOHB-204). The different residues are coloured in red, gaps are coloured in pink boxes and represented as dashes. 


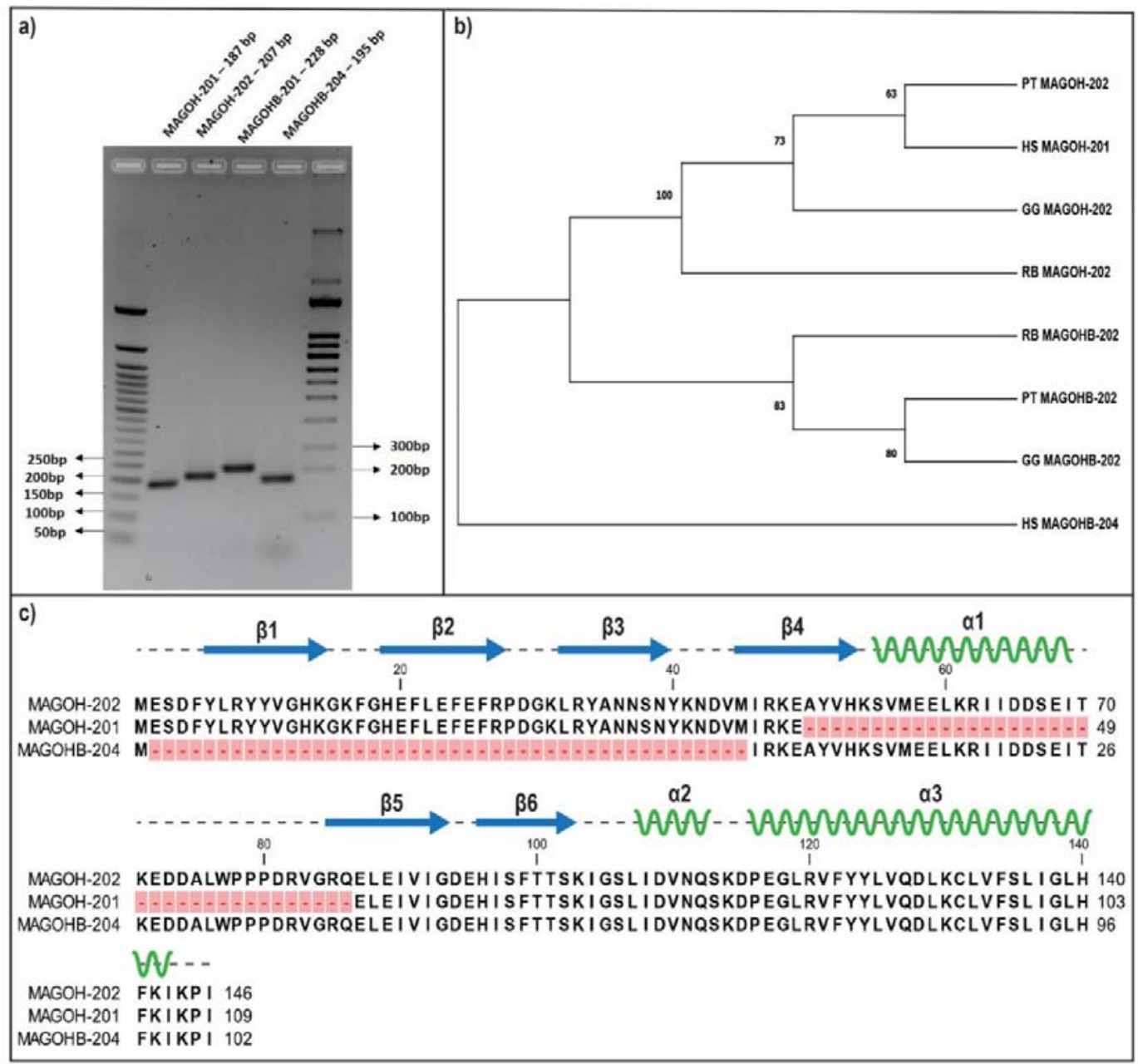

Figure-3 Analysis of alternate isoforms of MAGOH paralogs. a) The expression of alternate isoforms was validated in HEK-293 cells. The expected size of amplicons is mentioned in brackets. b) Phylogenetic tree for species expressing both the isoforms of MAGOH paralogs. The numbers on each node indicate bootstrap values for 500 replicates. PT- Pan troglodytes, HS- Homo sapiens, GGGorilla gorilla, RB- Rhinopithecus bieti. c) Structural comparison of alternate isoforms to the principal MAGOH isoform, MAGOH-202. MAGOH-202 is aligned with MAGOH-201 (109 amino acids, devoid of residues 50-86) and MAGOHB-204 (102 amino acids, lacking N-terminus residues 146). The gaps are represented in pink boxes. Secondary structures are represented above the alignment according to the crystal structure of MAGOH-Y14 (PDB ID 1P27), described by Lau et $\mathrm{al}^{15}$. Here, $\beta 1$ - 
407 Table 1- MAGOH paralog isoforms in Homo sapiens

\begin{tabular}{|c|c|c|c|c|c|c|c|c|c|c|c|c|}
\hline Transcript ID & Ensembl ID & $\begin{array}{l}\text { Length } \\
\text { (bases) }\end{array}$ & $\begin{array}{c}\text { Protein } \\
\text { (amino acids) }\end{array}$ & Biotype & $\begin{array}{c}\text { 5'UTR } \\
\text { (bases) }\end{array}$ & $\begin{array}{l}\text { Exon } 1 \\
\text { (bases) }\end{array}$ & $\begin{array}{l}\text { Exon } 2 \\
\text { (bases) }\end{array}$ & $\begin{array}{l}\text { Exon3 } \\
\text { (bases) }\end{array}$ & $\begin{array}{c}\text { Exon4 } \\
\text { (bases) }\end{array}$ & $\begin{array}{c}\text { Exon5 } \\
\text { (bases) }\end{array}$ & $\begin{array}{c}\text { Exon6 } \\
\text { (bases) }\end{array}$ & $\begin{array}{c}\text { 3'UTR } \\
\text { (bases) }\end{array}$ \\
\hline MAGOH-201 & ENST00000371466.4 & 500 & 109 & Protein-coding & 51 & $51^{*}+88$ & 59 & 83 & $100+119$ & - & - & 119 \\
\hline MAGOH-202 & ENST00000371470.8 & 656 & 146 & Protein-coding & 70 & $70+88$ & 59 & 111 & 83 & $100+145$ & - & 145 \\
\hline MAGOH-203 & ENST00000462941.1 & 738 & - & $\begin{array}{c}\text { Processed } \\
\text { transcript } \\
\text { (no ORF) }\end{array}$ & - & 148 & 59 & 531 & - & - & - & - \\
\hline MAGOH-204 & ENST00000495868.1 & 695 & - & $\begin{array}{l}\text { Processed } \\
\text { transcript }\end{array}$ & - & 398 & 83 & 214 & - & - & - & - \\
\hline MAGOHB-201 & ENST00000320756.7 & 2606 & 148 & Protein-coding & 77 & $77+94$ & 59 & 111 & 83 & $\begin{array}{l}100+ \\
2082\end{array}$ & - & 2082 \\
\hline MAGOHB-202 & ENST00000398874.8 & 549 & - & $\mathrm{IR}^{*}$ & - & 187 & 362 & - & - & - & - & - \\
\hline MAGOHB-203 & ENST00000537852.5 & 2671 & - & IR & - & 162 & 59 & 2088 & - & - & - & - \\
\hline MAGOHB-204 & ENST00000539554.5 & 666 & 102 & Protein-coding & 95 & 51 & $44+15$ & 111 & 83 & $100+262$ & & 262 \\
\hline MAGOHB-205 & ENST00000540074.5 & 705 & 44 & NMD* & 95 & 51 & $45+15$ & 111 & $9+277$ & 83 & 115 & 475 \\
\hline MAGOHB-206 & ENST00000543929.5 & 841 & 81 & NMD & 68 & $68+94$ & $152+187$ & 59 & 111 & 170 & - & 527 \\
\hline MAGOHB-207 & ENST00000544176.1 & 559 & - & IR & - & 162 & 59 & 338 & - & - & - & - \\
\hline MAGOHB-208 & ENST00000544850.5 & 1057 & 90 & NMD & 62 & $62+94$ & 59 & 111 & $9+277$ & 83 & 362 & 722 \\
\hline MAGOHB-209 & ENST00000545236.5 & 868 & 81 & NMD & 77 & $77+94$ & $152+187$ & 59 & 111 & 83 & 105 & 545 \\
\hline MAGOHB-210 & ENST00000546173.5 & 576 & 81 & NMD & 41 & $41+94$ & $152+12$ & 59 & 111 & 107 & - & 289 \\
\hline MAGOHB-211 & ENST00000625272.1 & 319 & 81 & Protein-coding & 73 & $73+94$ & 152 & - & - & - & - & - \\
\hline
\end{tabular}




\begin{tabular}{|c|c|c|c|c|c|c|c|c|c|c|c|c|}
\hline Transcript ID & Ensembl ID & $\begin{array}{l}\text { Length } \\
\text { (bases) }\end{array}$ & $\begin{array}{c}\text { Protein } \\
\text { (amino acids) }\end{array}$ & Biotype & $\begin{array}{c}\text { 5'UTR } \\
\text { (bases) }\end{array}$ & $\begin{array}{l}\text { Exon } 1 \\
\text { (bases) }\end{array}$ & $\begin{array}{l}\text { Exon } 2 \\
\text { (bases) }\end{array}$ & $\begin{array}{l}\text { Exon3 } \\
\text { (bases) }\end{array}$ & $\begin{array}{c}\text { Exon4 } \\
\text { (bases) }\end{array}$ & $\begin{array}{l}\text { Exon5 } \\
\text { (bases) }\end{array}$ & $\begin{array}{l}\text { Exon6 } \\
\text { (bases) }\end{array}$ & $\begin{array}{c}\text { 3'UTR } \\
\text { (bases) }\end{array}$ \\
\hline Magoh-201 & ENSMUST00000030348.5 & 692 & 146 & Protein coding & 103 & $103^{*}+88$ & 59 & 111 & 83 & $100+148$ & - & 148 \\
\hline Magoh-202 & ENSMUST00000141376.1 & 483 & - & Processed transcript & - & 189 & 83 & 211 & - & - & - & - \\
\hline Magohb-201 & ENSMUST00000032307.11 & 767 & 148 & Protein coding & 79 & $79+94$ & 59 & 111 & 83 & $100+241$ & - & 241 \\
\hline Magohb-202 & ENSMUST00000172883.7 & 460 & 35 & NMD* & - & 60 & $47+64$ & 83 & 206 & - & - & 353 \\
\hline Magohb-203 & ENSMUST00000173198.7 & 561 & 44 & NMD & - & 80 & $53+147$ & 59 & 111 & 83 & 28 & 428 \\
\hline Magohb-204 & ENSMUST00000173332.1 & 395 & 44 & NMD & - & 80 & $54+147$ & 59 & 56 & - & - & 262 \\
\hline Magohb-205 & ENSMUST00000173837.5 & 897 & 102 & Protein coding & 564 & 520 & $44+15$ & 111 & 83 & $100+24$ & - & 24 \\
\hline Magohb-206 & ENSMUST00000174488.1 & 447 & - & $\mathrm{IR}^{*}$ & - & 231 & 216 & - & - & - & - & - \\
\hline Magohb-207 & ENSMUST00000174781.3 & 546 & - & $\mathrm{IR}$ & - & 288 & 111 & 83 & 64 & - & - & - \\
\hline
\end{tabular}

410 Table 2- Magoh paralog isoforms in Mus musculus

$411 *$ NMD $=$ Nonsense-mediated mRNA decay, IR= Intron retention, * Number of bases written in red correspond to untranslated regions (UTR)

412

413 Table 3- Species with conserved alternate isoforms of MAGOH paralogs

\begin{tabular}{|c|c|c|}
\hline Gene & $\begin{array}{c}\text { Size of prote in } \\
\text { (amino acids) }\end{array}$ & Species with conserved isoform \\
\hline $\mathrm{MAGOH}$ & 109 & $\begin{array}{c}\text { Anser brachyrhynchus, Anser cygnoides, Aotus nancymaae, Bison bison bison, Bos grunniens, Hybrid - Bos Indicus (Bos indicus x Bos taurus), } \\
\text { Bos mutus, Hybrid - Bos Taurus (Bos indicus x Bos taurus), Callithrix jacchus, Camelus dromedarius, Canis lupus familiaris, Canis lupus } \\
\text { familiaris, Carlito syrichta, Catagonus wagneri, Cebus capucinus imitator, Cercocebus atys, Colobus angolensis palliatus, Equus caballus, Felis } \\
\text { catus, Gorilla gorilla gorilla, Homo sapiens, Lynx canadensis, Macaca fascicularis, Macaca nemestrina, Mandrillus leucophaeus, Microcebus } \\
\text { murinus, Monodelphis domestica, Moschus moschiferus, Neovison vison, Nomascus leucogenys, Ornithorhynchus anatinus, Oryctolagus } \\
\text { cuniculus, Bonobo, Pan paniscus, Pan troglodytes, Panthera leo, Panthera pardus, Panthera tigris altaica, Papio anubis, Physeter catodon, } \\
\text { Piliocolobus tephrosceles, Podarcis muralis, Prolemur simus, Propithecus coquereli, Rhinolophus ferrumequinum, Rhinopithecus bieti, } \\
\text { Rhinopithecus roxellana, Saimiri boliviensis boliviensis, Suricata suricatta, Sus scrofa, Theropithecus gelada, Ursus thibetanus thibetanus, } \\
\text { Vombatus ursinus }\end{array}$ \\
\hline
\end{tabular}


MAGOHB

102

.
Cavia porcellus, Cricetulus griseus, Dipodomys ordii, Gorilla gorilla gorilla, Homo sapiens, Mus musculus, Mus pahari, Mus spretus, Nannospalax galili, Pan troglodytes, Rhinopithecus bieti

414

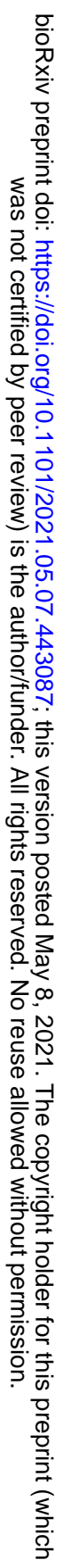

